\title{
Dysphagia in inclusion body myositis
}

\author{
A R WINTZEN,* G Th A M BOTS, $\dagger$ H M de BAKKER, $\ddagger$ J H HULSHOF,§ G W PADBERG* \\ From the Department of Neurology,* Pathology, $\dagger$ Neuroradiology $\ddagger$ and Otolaryngology of the University \\ Hospital, Leiden, The Netherlands
}

SUMMARY Four elderly patients with inclusion body myositis and dysphagia are described. Dysphagia was the presenting symptom in three, preceding generalised weakness by 1.5 to 7 years. Myotomy of the cricopharyngeal muscle improved the symptoms and signs in 3 of the 4 patients. It is suggested that inclusion body myositis is not an infrequent cause of dysphagia in elderly people, and is amenable to treatment.

During the last few years inclusion body myositis (IBM) has generally been accepted as a clinically and pathologically distinct disorder. ${ }^{1-6}$ Clinically it is characterised by a chronic progressive course, preferential affliction of elderly people, both proximal and distal muscular weakness and virtual resistance to treatment with steroids, immunosuppression, plasmapheresis and total body radiation. Pathologically, important features, besides those of myositis, are "rimmed vacuoles", intracytoplasmic and intranuclear eosinophilic inclusion bodies and groups of atrophic fibres, the latter suggesting accompanying neural involvement. Ultrastructurally the inclusion bodies appear to consist of masses of tubular filaments $15-20 \mu \mathrm{m}$ in diameter. The cause of the disease is unknown: an infection with incomplete mumps virus has recently been implicated by Chou and Örvell, ${ }^{7}$ an as yet unconfirmed finding.

Dysphagia in IBM patients, with a few exceptions, ${ }^{1689}$ is considered to be rare. ${ }^{2510-14}$ Its exact nature and mechanism has not been studied. In this paper we report four patients with IBM with severe dysphagia. The clinical, radiological and pathological findings in these patients will be described as well as the results of surgical treatment.

\section{PATIENTS}

Between January 1985 and July 1987 we observed six patients with IBM, four of whom had dysphagia. The dysphagic patients were 60 years or over when first seen. Three were female (table 1). Dysphagia preceded the generalised weakness in three patients by $1 \cdot 5,2$ and 7 years respectively. The EMG revealed a myopathic pattern in all, and neurogenic

Address for reprint requests: A R Wintzen, Department of Neurology, University Hospital, Rijnsburgerweg 10, 2333 AA, Leiden, The Netherlands.

Received 31 May 1988.

Accepted 1 July 1988 features in two. Two patients had been treated with prednisone without beneficial effect. Creatine kinase was slightly to moderately elevated in all. Specific additional clinical features included rheumatoid arthritis and mumps infection at an advanced age (51) in case 1 , and a history of hyperthyroidism in case 3 .

\section{MUSCULAR BIOPSY FINDINGS}

A quadriceps muscle biopsy was obtained from all patients $\frac{O}{\mathrm{~T}} \mathrm{~N}$ At the cricopharyngeal myotomy a second biopsy was taken? from the omohyoid muscle because this muscle has to be severed in the surgical procedure. An omohyoid muscleo biopsy was not available from patient 4 , in whom the cricopharyngeal muscle itself was biopsied.

All biopsy specimens were quenched in liquid nitrogen for the preparation of cryostat sections including at leasto. haematoxylin and eosin, ATP-ase, NADH-TR, acid phos? phatase, modified Gomori trichrome, Oil-Red $O$ and PAS staining.

All specimens showed both perivascular and endomysial lymphocytic infiltration as well as necrotic and regenerating fibres (table 2). "Rimmed vacuoles" were a common feature to all patients (fig 1). Eosinophilic intranuclear and/or cytoplasmic inclusions were seen in most instances. Inter-

\section{Table 1 Clinical characteristics of patients}

\begin{tabular}{lccccc}
\hline & \multicolumn{1}{c}{ Case 1} & Case 2 & Case 3 & Case 4 \\
\hline Age at examination & 76 & 60 & 67 & 74 \\
Sex & $\mathrm{M}$ & $\mathrm{F}$ & $\mathrm{F}$ & $\mathrm{F}$ \\
Duration of illness (years) & 4 & 2 & 8 & 10 \\
Duration of dysphagia & 4 & $0 \cdot 5$ & 8 & 10 \\
$\begin{array}{l}\text { Duration of dysbasia } \\
\text { Proximal weakness }\end{array}$ & 4 & 2 & 6 & 3 \\
$\begin{array}{l}\text { Distal weakness } \\
\text { EMG: "myopathic" pattern }\end{array}$ & + & + & + & + \\
$\begin{array}{l}\text { EMG: "denervation" pattern } \\
\text { Treatment with prednisone: dose } \\
\text { (mg/day) }\end{array}$ & - & - & + & + \\
$\begin{array}{l}\text { duration (year) } \\
\text { result }\end{array}$ & - & 30 & - & 10 \\
$\begin{array}{l}\text { Creatine kinase (times normal } \\
\text { upper limit) }\end{array}$ & - & $1 \frac{1}{2}$ & - & $\frac{1}{2}$ \\
\hline
\end{tabular}



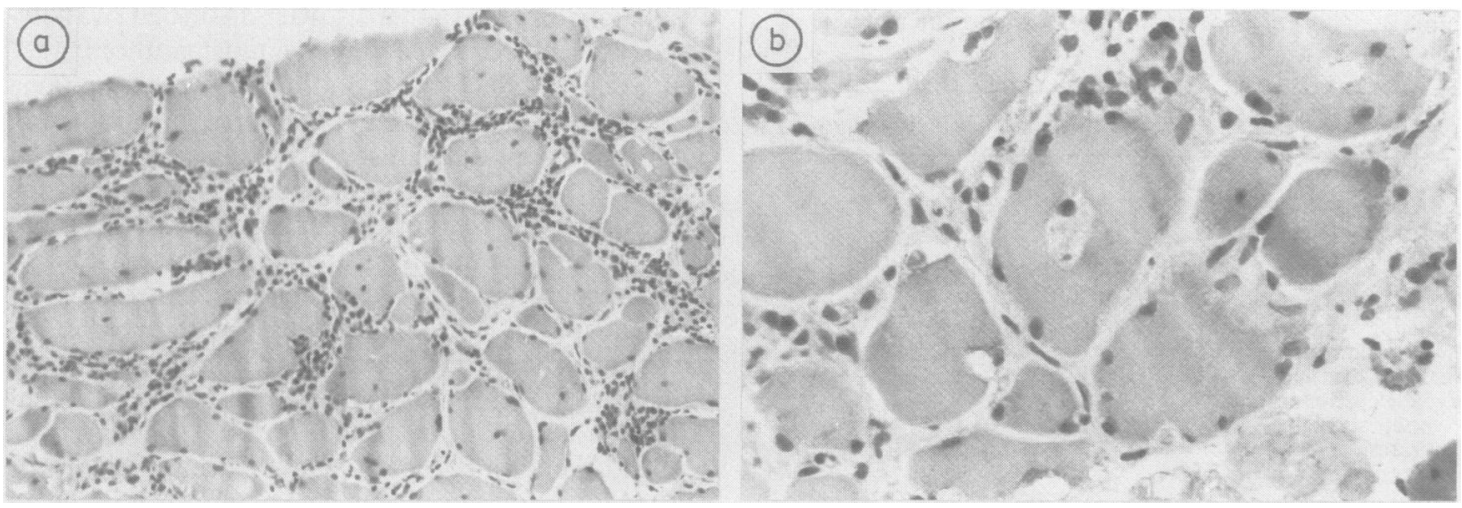

Fig 1 (A): Biopsy of quadriceps muscle case 1. Note atrophic and hypertrophic fibres, central nuclei, vacuoles and interstitial mononuclear infiltration (cryostat, HE, $\times 160),(B)$ : "rimmed vacuoles" (cryostat. HE, $\times 400$ ).

stitial fibrosis indicated long standing disease in all. Although the intensity of abnormalities varied considerably between the patients, they were more marked in the quadriceps than in the omohyoid muscles.

At the time of surgery in the fourth patient the previous three had been fully studied and we wondered whether the cricopharyngeus muscle, which seemed to be spared clinically and radiologically, was affected pathologically. Although the muscle appeared as a thick strand of muscle fibres to the surgeon, histological examination revealed mainly fibrous tissue and fat, with only a few muscle fibres, which were completely normal.

\section{DYSPHAGIA}

All patients reported a feeling of lower pharyngeal obstruction for solid food; the patients $\mathbf{3}$ and $\mathbf{4}$ also had difficulty with passing fluids (table 3 ). These two patients experienced nasal reflux as well. All patients aspirated frequently during their meals, which, moreover, required more time than was socially acceptable to them. It is important to note that all patients except No 2 had been previously examined by several physicians including radiological investigation of swallowing in the cases 1 and 4, but that a myopathic cause was not considered before generalised weakness became obvious.

Before cricopharyngeal myotomy a 3 frames per second cineradiographic examination of swallowing movements was performed and a 25 frames per second video-radiographic investigation thereafter, as the latter facility was not available initially. The findings were similar in the four patients, although the extent of the abnormalities varied widely (table 3). There was paretic widening of the hypopharynx in all, which, however, was excessive in cases 1 and 3 (fig 2a). A Zenker's pulsion diverticulum was an additional finding in case 1. All patients had a prominent posterior indentation as a result of contraction of the cricopharyngeus muscle at the moment that the hypopharynx was still dilated and filled with residual contrast material (fig 2b). Cranially directed movement of the hyoid bone during swallowing was measured and expressed as heights of the $\mathrm{C} 3$ or $\mathrm{C} 4$ vertebra. It exceeded one such dimension in all patients. Aspiration was documented in three. Cricopharyngeal myotomy was performed in all four patients. Patient 3 was the only one denying any benefit from myotomy. To our surprise, postoperative radiological examination revealed no evidence of change in the function of the muscle. The patient refused reoperation. The remaining patients reported considerable improvement in swallowing comfort and duration of meals. In these patients the radiological counterpart of improved function was virtual disappearance of posterior indentation by the cricopharyngeus muscle. One patient (case 4) claimed disappearance of choking, although aspiration was seen radiologically after surgery.

Table 2 Abnormalities in biopsies of quadriceps (Q) and omo-hyoid $(\mathrm{OH})$

\begin{tabular}{|c|c|c|c|c|c|c|c|c|}
\hline \multirow{2}{*}{$\begin{array}{l}\text { Case } \\
\text { Muscle }\end{array}$} & \multicolumn{2}{|l|}{ Case 1} & \multicolumn{2}{|l|}{ Case 2} & \multicolumn{2}{|l|}{ Case 3} & \multicolumn{2}{|c|}{ Case 4} \\
\hline & $\bar{Q}$ & $O H$ & $\bar{Q}$ & $O H$ & $Q$ & $O H$ & $Q$ & $*$ \\
\hline $\begin{array}{l}\text { Mononuclear infiltration: } \\
\text { perivascular } \\
\text { endomysial } \\
\text { Necrotic fibres } \\
\text { Regenerating fibres } \\
\text { "Rimmed vacuoles" } \\
\text { Eosinophilic intranuclear inclusions } \\
\text { Eosinophilic cytoplasmic inclusions } \\
\text { Interstitial fibrosis }\end{array}$ & $\begin{array}{l}+++ \\
+++ \\
++ \\
++ \\
++ \\
+ \\
+ \\
+\end{array}$ & $\begin{array}{l}+ \\
+ \\
++ \\
++ \\
++ \\
+ \\
+\end{array}$ & $\begin{array}{l}+++ \\
+++ \\
++ \\
+ \\
++ \\
++ \\
++ \\
+\end{array}$ & $\begin{array}{l}++ \\
++ \\
+ \\
+ \\
+ \\
+ \\
+\end{array}$ & $\begin{array}{l}+++ \\
+++ \\
++ \\
++ \\
++ \\
+++ \\
+ \\
+\end{array}$ & $\begin{array}{l}+++ \\
+++ \\
+ \\
+ \\
+ \\
- \\
+\end{array}$ & $\begin{array}{l}++ \\
++ \\
++ \\
++ \\
++ \\
+ \\
+ \\
+\end{array}$ & $\begin{array}{l}1 \\
1 \\
1 \\
1 \\
1 \\
1 \\
1 \\
1\end{array}$ \\
\hline
\end{tabular}

*Not available, see text; + indicates: mild or few; ++ indicates: moderate or several; +++ indicates: severe or many. 
Table 3 Clinical and radiological characteristics of dysphagia

\begin{tabular}{|c|c|c|c|c|}
\hline & Case 1 & Case 2 & Case 3 & Case 4 \\
\hline $\begin{array}{l}\text { Symptoms } \\
\text { Obstruction solids } \\
\text { Obstruction fluids } \\
\text { Nasal reflux } \\
\text { Aspiration/choking } \\
\text { Radiological findings } \\
\text { Widening hypopharynx } \\
\text { Posterior indentation CPM } \\
\text { Zenker's diverticulum } \\
\text { Hyoid elevation (number of } \\
\text { vertebral heights) } \\
\text { Aspiration } \\
\text { Results of CP myotomy } \\
\text { Aspiration/choking } \\
\text { Time needed for meals }\end{array}$ & $\begin{array}{l}+ \\
- \\
- \\
+ \\
++(\mathrm{U}) \\
++(\mathrm{I}) \\
+(\mathrm{I}) \\
1 \cdot 6 \\
+(\mathrm{I}) \\
\operatorname{good} \\
\text { good }\end{array}$ & $\begin{array}{l}+ \\
- \\
- \\
+ \\
+(\mathrm{U}) \\
+(\mathrm{I}) \\
- \\
1 \cdot 2 \\
-(\mathrm{U}) \\
\text { good } \\
\text { good }\end{array}$ & $\begin{array}{l}+ \\
+ \\
+ \\
+ \\
++(U) \\
+(U) \\
- \\
1 \cdot 2 \\
++(U) \\
\text { no } \\
\text { no }\end{array}$ & $\begin{array}{l}+ \\
+ \\
+ \\
+ \\
+(U) \\
+(I) \\
- \\
1 \cdot 5 \\
+(U) \\
\text { good } \\
\text { good }\end{array}$ \\
\hline
\end{tabular}

In brackets: postoperative findings: $U$ indicates unchanged, $I$ indicates improved.

\section{Discussion}

Documented studies of the mechanism and treatment of dysphagia in inflammatory myopathies in general are scarce. ${ }^{1516-19}$ We have not found a description of dysphagia in IBM. In this disorder disturbed swallowing is considered to be rare by most authors, ${ }^{2510-14}$ though not by all. ${ }^{1689}$ Our finding of severe dysphagia in four out of six cases may, of course, be accidental, but might have other causes. Dysphagia of ill-defined nature ${ }^{19-21}$ is not uncommon in elderly people which may contribute to the frequent failure to diagnose IBM. Several authors have suggested that IBM is under-recognised because of lack of awareness of its frequency ${ }^{1214}$ or lack of familiarity with the clinicopathological features. ${ }^{114}$ In three of our four patients a diagnosis of "idiopathic" dysphagia had been maintained for up to 7 years.

IBM, like all inflammatory myopathies, cannot be defined by a single criterion. The diagnosis is made on the basis of a combination of clinical, biochemical and pathological findings. ${ }^{5614}$ As our patients had a slowly progressive inflammatory myopathy at an advanced age, with slightly elevated creatine kinase value and both rimmed vacuoles and eosinophilic inclusions in their biopsies, we feel that a diagnosis of IBM is warranted. In three of the four patients an additional omohyoid muscle biopsy documented IBM

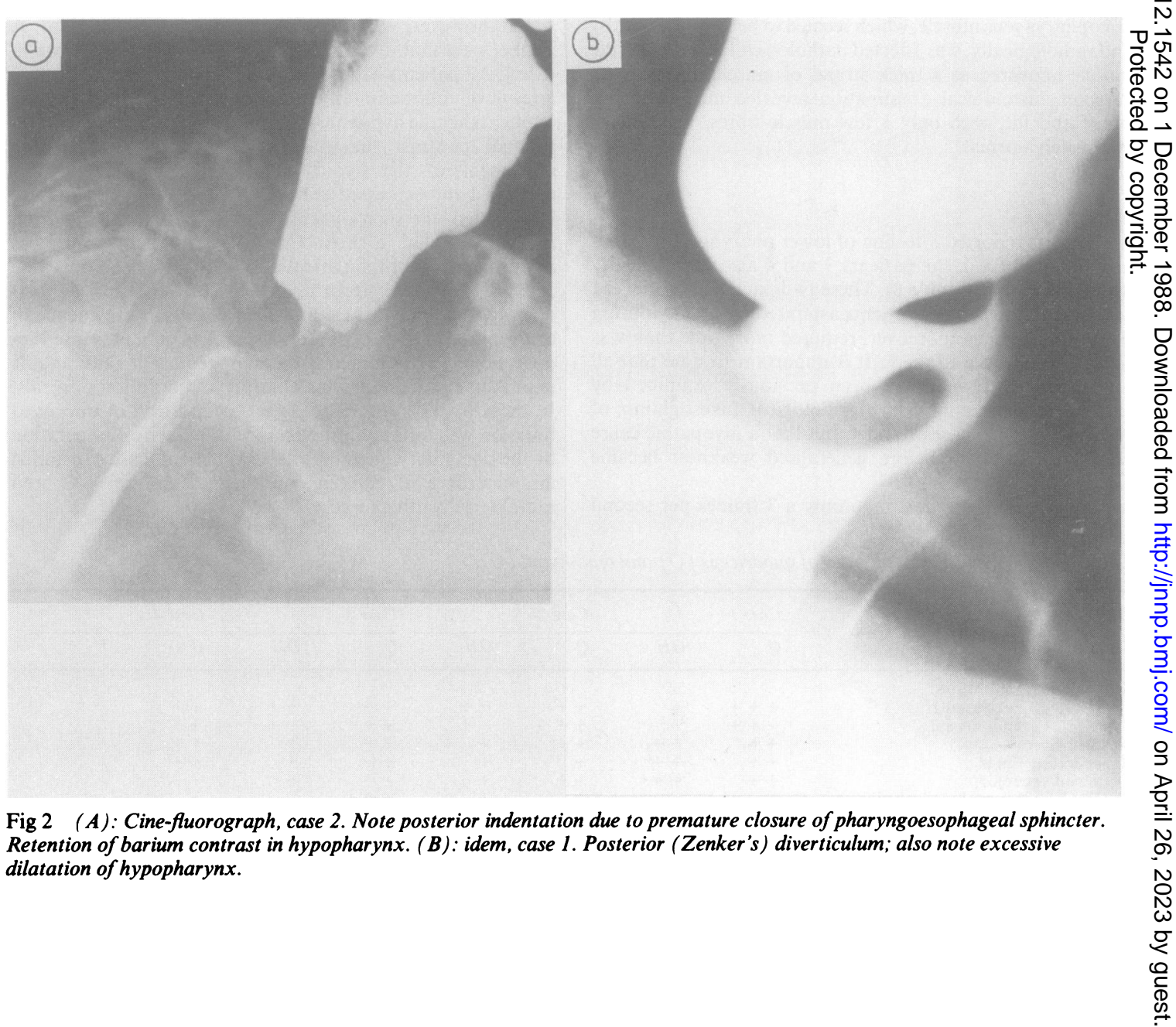


as the cause of pharyngeal weakness, thus excluding other disorders or "ageing". The mechanism of the dysphagia was similar in all four patients: paresis of the pharyngeal wall precluded a timely emptying of the pharynx before the upper esophageal sphincter was closed, resulting in repetitive swallowing for one bolus and choking. This mechanism conforms to that described in lower motor neuron disorders and myopathies. ${ }^{192223}$ For this type of dysphagia cricopharyngeal myotomy is widely advocated, although it is not helpful in a proportion of cases. ${ }^{123-25}$ The reason for this failure is not always clear..$^{25}$ The surgeon may have performed an incomplete section, ${ }^{23}$ the residual force of the pharyngeal wall may be insufficient to empty the lumen even in the absence of a sphincter, ${ }^{1926}$ or the elevation of the larynx may be too small to free the entrance of the oesophagus. ${ }^{25}$ In case 3 , weakness and dilation of the pharynx was excessive and the laryngeal elevation moderate. Postoperative videofluoroscopy, however, suggested incomplete severance of the CPM.

We conclude that IBM may be a not infrequent cause of dysphagia in elderly people. Swallowing disorder may be a presenting symptom of the disease. In these patients asymptomatic weakness should be looked for. Cricopharyngeal myotomy may benefit a large proportion of these patients.

\section{References}

1 Carpenter S, Karpati G, Heller J, Eisen A. Inclusion body myositis: a distinct variety of idiopathic inflammatory myopathy. Neurology 1978;28:8-17.

2 Danon MJ, Reyes MG, Perurena OH, Masdeu JC, Manaligod JR. Inclusion body myositis: a corticosteroid-resistant idiopathic inflammatory myopathy. Arch Neurol 1982;39:760-4.

3 Mastaglia FL, Ojeda VJ. Inflammatory myopathies: Part 2. Ann Neurol 1985;17:317-23.

4 Chou SM. Inclusion body myositis. A possible chronic persistent muscle infection by mumps virus. Cleve Clin $Q$ 1985;52:583-9.

5 Mikol J. Inclusion body myositis: In: Engel A, Banker BQ, Myology, Basic and Clinical. New York: McGraw-Hill, 1986: 1423-38.

6 Ringel SP, Kenny CE, Neville HE, Giorno R, Carry MR. Spectrum of inclusion body myositis. Arch Neurol 1987; 44:1154-7.

7 Chou SM, Orvell. Localization of mumps virus structural proteins with monoclonal antibodies in muscles of inclusion body myositis. Ann Neurol 1987;22:129-30.

8 Jersalem F, Baumgartner G, Wyler R. Virus-ähnliche Einschlüsse bei chronischen neuro-muskulären Prozessen. Arch Psychiat Nervenkr 1972;215:148-66.

9 Lazaro RP, Barron KD, Dentinger MP, Lava NS. Inclusion body myositis: case reports and a reappraisal of an underrecognized type of inflammatory myopathy. Mount Sinai J Med 1988;53: $137-44$.

10 Eisen A, Berry K, Gibson G. Inclusion body myositis: myopathy or neuropathy? Neurology 1983;33:1109-14.

11 Chou SM. Inclusion body myositis: a chronic persistent mumps myositis? Hum Pathol 1986;17:765-77.

12 Karpati G. Pathogenesis and management of idiopathic inflammatory myopathies. Muscle Nerve 1986;9 suppl:93.

13 Baysal AI, Joy JL, Oh SJ. Clinical spectrum in inclusion body myopathy. Ann Neurol 1987;22:164.

14 Calabrese LH, Mitsumoto H, Chou SM. Inclusion body myositis presenting as treatment resistant polymyositis. Arthritis Rheum 1987;30:397-403.

15 Silbiger ML, Pikielny R, Donner MW. Neuromuscular disorders affecting the pharynx. Invest Radiol 1967;2:442-8.

16 Dietz F, Logeman JA, Sahgal V, Schmid FR. Cricopharyngeal muscle dysfunction in the differential diagnosis of dysphagia in polymyositis. Arthritis Rheum 1980;23:491-5.

17 Jacob H, Berkowitz D, McDonald E, Bernstein LH, Beneventano Th. The esophageal motilty disorder in polymyositis. A prospective study. Arch Intern Med 1983;143:2262-4.

18 Merieux P de, Verity MA, Clements PJ, Paulus HE. Esophageal abnormalities and dysphagia in polymyositis and dermatomyositis. Clinical, radiographic and pathological features. Arthritis Rheum 1983;26:961-8.

19 Schmid H, Wolfensberger M, Augustiny N, Brühlmann W. Cricopharyngus-Myotomie bei Dysfunktion des pharyngoösophagealen übergangs. HNO 1987;35:425-9.

20 Piaget F, Fouillet J. Le pharynx et l'oesophage séniles. Etude clinique, radiologique et radiocinématographique. J Méd Lyon, 1959;40:951-66.

21 Borgström PS, Ekberg $O$. Pharyngeal dysfunction in the elderly $J$ Med Imag 1988;2:74-81.

22 Kaplan S. Paralysis of deglutition, a post-poliomyelitis complication treated by section of the cricopharyngeus muscle. Ann Surg 1951;133:572-3.

23 Overbeek JJM van, Betlem HC. Cricopharyngeal myotomy in pharyngeal paralysis. Cineradiographic and manometric indications. Ann Otol Rhinol Laryngol 1979;88:596-602.

24 Palmer ED. Disorders of the cricopharyngeus muscle, a review. Gastroenterology 1976;71:510-9.

25 Goyal RK. Disorders of the cricopharyngeus muscle. Otolaryngol Clin North Am 1984;17:115-30.

26 Berg HM, Persky MS, Jabobs JB, Cohen NL. Cricopharyngeal myotomy: a review of surgical results in patients with cricopharyngeal achalasia of neurogenic origin. Laryngoscope 1985;95:1337-40.

27 Mendelssohn MS, McConnel FM. Function of the pharyngoesophageal segment. Laryngoscope 1987;97:483-9. 